\title{
Temporal existentiality: the objectification of subjectivity
}

\author{
Natalia Serova ${ }^{1 *}$, Lyudmila Pendurina ${ }^{2}$ and Alexander Fedoseenkov ${ }^{2}$ \\ ${ }^{1}$ Admiral F. F. Ushakov State Maritime University, Novorossiisk, 353918, Russia. \\ ${ }^{2}$ Don state technical University, Rostov-on-Don, 344002, Russia.
}

\begin{abstract}
The turn from mass consumption to the creation of new and unique works in the development of contemporary culture, education and science is more and more clearly outlined. It is important to change not only our attitude to cultural and scientific achievements, but also to the person who creates them. The problem of temporality in its counteraction to objectification of human existence is considered in the article. The reasons for objectification of human subjectivity are analyzed and its mechanisms are revealed. The essence of the dilemma of objective and subjective time is revealed. There is the result of identification of the attributive properties of temporality. The unity of all modes of temporality, its ecstatic and constitutional nature are among them. The authors conclude that the study of the problem of temporality is an important step towards changing the consumer attitude of a person to culture and to himself. $\mathrm{He}$ must comprehend his own temporal nature as a condition for creative activity, which is highly valued in the modern culture, oriented by innovations.
\end{abstract}

\section{Introduction}

Since the nineteenth century, the popularity of scientific knowledge was only increasing. It was adopted as the basis for the development of culture and the knowledge of man. In the XIX-XX centuries, the Humanities received a powerful impetus and included sociology, psychology, psycholinguistics, art history and religious study. The comprehensive research of person by the Humanities has led to an increase of the objectification of his subjectivity. It may seem that we know everything about a person: his needs, interests, habits, feelings and desires. However, as a rule, we do not mean a concrete individual, but a typical person. Therefore the success of mass production, mass consumption and mass culture becomes clear. Having reached a certain degree of comfort and security, the mass man feels dissatisfaction with his lack of realization. However, the habit of accepted standards as a consequence of the objectification of subjectivity becomes an obstacle to his creative development.

At the beginning of the twentieth century, this orientation of consciousness prompted philosophers to seek the such basis of subjectivity, which would become a counteraction to its objectification. The search led to the discovery of temporality. In this article it is

\footnotetext{
*Corresponding author: nserova1@rambler.ru
} 
proposed to consider the question of how temporality as a constituent of human existence counteracts its objectification. In achieving this goal, it is necessary: first, to understand the nature of objectification and its effects on human subjectivity. Secondly, to compare and identify the difference between objective time and subjective time for that to determine the limit of objectification of subjectivity. Thirdly, to identify those attributive properties of temporality, due to which the objectification of human existence becomes impossible. The topic of temporality of human existence is studied by foreign $[1,2,3]$ and Russian researchers $[4,5,6]$. However, in their works the problem of objectification of subjectivity through the orientation of person to objective time is not considered and temporality is not represented by the basis of human existence, which could resist this. In the conditions of crisis of mass society it is necessary to reveal people with creative potential and to stop any attempts of objectification of the person therefore development of this topic seems timely to us.

\section{From exteriorization to the objectification of human's subjectivity}

Culture is the result of the exteriorization of the inner life of person in the external world. The subjectivity of person is imprinted in the cultural symbols, which he own creates. Symbols are connected with it in their content, so it, embodied in them, turns in the part of the external world. As a result, subjectivity is alienated from person and it is perceived as part of the objective world. Because of the diversity and increasing number of objects that satisfy the needs of person, he sees no sense in education, creativity and freedom of thought. Person aims not at the production of ideas, but at the consumption of things. E. Balas believes that "a large number of research failures come from the lack of the diversity of thought" [7]. But how to determine the line, crossing which, a person falls into the power of the objective world, dictating him conditions of existence?

H. Bergson and E. Husserl searched for the boundary beyond which exteriorization stops and the objectification of human subjectivity begins. Defending the priority of subjectivity in the development of culture, they opposed the objectification of the inner world of person. H. Bergson recognized the signs of objectification of subjectivity under the guise of its exteriorization. He believed that we objectify the image of an object that is reproduced in the mind every time we move from the concept of its uniqueness and consider it along with other objects. Defining the essence of objectification, A. Bergson notes that "this actual and not merely virtual perception of subdivisions in what is undivided is just what we call objectivity" [8]. The object is an infinitely divisible sequence and is itself part of multiplicity. Whereas subjectivity is characterized by integrity and synthesis of its content. Cognizing the objective world, a person thanks to the abilities of his consciousness sees it not scattered but interconnected. However, focusing on the surface impressions of objects, consciousness obeys the logic of their discrete existence. The connection between superficial impressions and deep experiences of the inner life of a person is lost. A person ceases to value his inner world and begins to be guided only by external circumstances.

E. Husserl reveals the "objective attitude" [9] of human consciousness, guided by which it is oriented to the external world as an objective and real being. The primary exteriorization of the spirit leads to the universalization and spiritualization of nature. "In this way all psychic events, those of this or that ego, such as experience, thinking, willing, have a certain objectivity" [9]. As a result, the inner world of a person is identified with a variety of psychophysical phenomena. If subjectivity is derived from the psychophysical existence of a person then any manifestation of it is objectified. Objectification destroys the 
integrity of the inner world of person and he may lose the ability to produce original works and values of culture.

Continuing the research of this problem, M. Heidegger considers the mechanism of objectification through the consumer attitude of a person to the objects of his activity. A person establishes relations with objects as if any of them were only a means to the realization of his goals. G. Harman recognize for Heidegger the discovery of "ontology of objects themselves" [1], in which is held the distinction between the handiness and objectively present. Although man uses objects as instruments of his activity, but by caring for them he falls into their power. Because of this attitude toward objects, man begins to think of himself as a tool. "Being-in-the-world, as taking care of things, is taken in by the world which it takes care of" [10]. If a person changes his attitude to objects, he himself will not be subjected to objectification. G. Harman believes that contemporary philosophy should recognize that "the objects themselves are already more than objectively present" [1]. Drawing a distinction between the two forms of being - human existence and objectively presence, M. Heidegger hoped that a man would never become one of these things. However, in our opinion, his hopes have not yet been fulfilled. Contemporary man is so involved in the world of things and symbols that he is willing to sacrifice his life for them, but that same he commits an offence against his subjectivity.

Today, man begins to understand the perniciousness of a way of life in which there is no possibility for exteriorization of his subjectivity. He sees that the desire to possess symbols of prestige or power replace with itself all that he values. But man reveals the power of time over himself at the first attempt to change life in the direction from objectification to exteriorization of his subjectivity. It becomes the most ruthless dictator in the objective world for man. But is the force of time objective?

\section{The dilemma of objective time and subjective time}

At the beginning of the twentieth century, philosophers drew a line between objective time and subjective time to show that it is not the same in relation to different aspects of being and that a person has a chance to be free from the objectified existence. One of the important arguments in favor of this thesis was the doctrine of H. Bergson on duration. It is regarded by him as a sequence of fused conditions of consciousness. Feelings connect together and penetrate each other such a way that they cannot be divided. Duration as a synthesis of feelings is a measure of their depth and power of impact, but not of their number. Deep feelings are connected in one whole, and not located sequentially one after another. That is why duration differs from spatial notions of the location of objects in the external world. Comparing the duration and space, Yu. Novikov notes as the cause of the concept about mathematical time "decomposing activity of intellect" [11]. But he does not take into account the Bergson's idea about the human's habit to associate the concept of "multiplicity" [8] with the sequence of experiences associated with material objects. Duration belongs to our consciousness and contains "time as quantity" and "time as quality" [8] as their different forms. They belong to different levels of the human's inner world: time as quantity is a measure of shallow emotions caused by external objects, and time as quality is a measure of deep feelings, independent of external circumstances. One is characterized by static, homogeneous and discrete moments, and the other is characterized by their dynamism, heterogeneity and synthesis. There is a dilemma between the two forms of time, that it follows from the them comparison. Analyzing the dilemma of time as quality and time as quantity, $\mathrm{H}$. Bergson did not deny the possible correlation and mutual influence between them. He believed that "as this deeper self forms one and the same person with the superficial ego, the sum to endure in the same way" [8]. 
The experiences, formed under the influence of the perception of development and characteristics of the objective world, determine the nature of time as quantity. Because superficial feelings are associated with deeper experiences, they extend their inherent properties to them. Thus, deeper experiences become dependent on objects and lose their dynamism, integrity and diversity. This is the essence of the objectification of human subjectivity. According to $\mathrm{H}$. Bergson, we can keep our inner world from the destroying action of objectification by distinguishing superficial sensations from deeper experiences of our consciousness. By focusing our attention on our inner experiences, we can see the new and special features in usual objects. We form a different attitude to objects under the influence of the logic of time as quality, in which they cease to be a means of objectification of our inner world. This is the essence of the reverse transition from objectification to exteriorization of our subjectivity.

E. Husserl believed that the dilemma between objective time and subjective time is that one is transcendent and the other is immanent in relation to consciousness. By concentrating phenomenological analysis on the learning of the content of consciousness, the philosopher excludes objective time from it. However, as noted by V.Molchanov, objective time is "excluded" as "independent of consciousness" time and is restored as a problem of consciousness of objective time" [4]. Describing its characteristics, Husserl notes reality, discreteness, homogeneity, stability and calculus among them. He used the concept of "time-consciousness" [12] for designation of subjective time. Determined by own internal synthesis, it contains two levels: the perception of the time of the commission of objective phenomena (similarly time as quantity) and the feeling of the time of the flow of experiences in consciousness (similarly time as quality). Distinction between the sensation of time and the perception of time, E. Husserl comes to the discovery of "temporal apprehension-contents" [12], which determine the immanent experiences of time. V.Molchanov notes that Husserl "does not deny the existence of objective time, but raises the question of the strict difference between objective and subjective time" [4]. He explains the absence of such a difference by the fact that the duration of the object's existence and the duration of its experience in the perceiving consciousness are interconnected. He discovers both the objectification of the subjective time of consciousness and the subjectivation of the objective time of the material world in this relation. E. Husserl considers objectification of subjective time as coincidence of experiences of consciousness with material objects. He believes that "the coincidence concerns of the extratemporal material, which is preserved in the flow precisely as the identity of objective sense" [12]. The immutability of the meanings of objects is superimposed on the internal flow of experiences and thus "time-consciousness" [12] is objectified. At the same time, different moments of a natural phenomenon occurring in objective time are held in their unity due to retention. Thus, the reverse process of transformation of the moments of objective time into the moments of subjective time takes place. The complete transition of one time to another does not occur, since objective time is determined by the properties of matter, and subjective time - by the properties of "absolute subjectivity" [4]. Husserl's thesis that our subjectivity will never be definitively objectified follows from the difference between subjective and objective time.

H. Bergson and E. Husserl come to the common belief that the subjective time of our consciousness is different from the objective time of nature. Both believed that the knowledge about this difference will be a support in the struggle for the preservation of the inner world of person. However, if $\mathrm{H}$. Bergson established only the distinctive characteristics of subjective time and objective time, E. Husserl deduced the difference of their bases. If $\mathrm{H}$. Bergson showed the mechanism of objectification of subjectivity, E. Husserl came to the discovery of the mechanism of subjectification of objectivity. Developing the conceptions of subjective time, both philosophers prepared a turn from the 
cult of consumption to the ideal of production of cultural values. We see this cultural turn as the beginning of a large-scale development of the innovation society, for which creative people are needed. However, it was still necessary to substantiate the idea that temporality determines not only consciousness, but also the entire human's existence.

\section{Temporality of human's existence as a condition of his innovative activity}

The Heidegger's concept differs from the previous teachings in that, according to it, time determines the human's being, which is the unity of his essence and existence. The German philosopher introduces the concept of temporality that to emphasize its constitutive significance in relation to human existence, and separates it from the usual concept of time. "Because the expression "temporal" belong to both prephilosophical and philosophical usage, and because that expression will be used in different sense in the following investigation, we shall call the original determination of the meaning of being and its characters and modes which devolve from time its temporal determination" [10]. The introduction of this term in philosophy was due to the fact that M. Heidegger wanted to emphasize the special nature of human existence in time. The constitutive meaning of temporality is expressed in the fact that the essence and existence of person are determined not by external and independent conditions, but by him. Person seeks sensible existence and finds meaning in the unity of all the moments of his life. Nothing can be excluded from it, since "the meaning of being is in time" [13]. This quality of temporality Heidegger expressed in the following definition "we call the unified phenomenon of the future that makes present in the process of having-been temporality" [10]. Temporality is a condition for the integrity and sensible of human existence, because it is not divided into mutually exclusive moments of the past, present and future.

Ecstatic essence is another important feature of temporality, reflected in the fact that all the points in a temporary human existence are represented in the relation and mutual generation. The past as the "ecstasy of temporality" [10] indicates that the past event did not end, but came true. The present shows how everything comes true. The future is represented by the opportunities opening up for man. The ecstatic nature of temporality is universal for human existence. It did not follow that the dilemma of objective and subjective time did not exist. It is presented as the antithesis of "authentic temporality" and the "inauthentic temporality" [10] of human's existence in Heidegger's teaching. They are different aspects of human existence, expressing its attitude to the objective world and the public in Heidegger's theory. Thus, the dilemma of subjective and objective time leads us to a difficult choice: either to remain an independent person, or to submit to the power of object's existence. Obeying external circumstances and necessity, people do not see the prospects of their own future and cannot understand the value of innovative orientation of contemporary culture. However, as opinion by Ch. Bouton, "The time of human existence is not subject to the mechanical causality of nature, at least not in the sense of a predeterminism requiring that any future action be necessarily predetermined by present and past causes, therefore predictable in principle" [7]. Temporality prevents the objectification of human existence by virtue of its attributes. First, the constitutive nature of temporality defines a human's existence as specific mode of being that cannot be objectified. Secondly, the integrity of temporality as the unity of the past, present and future and this unity should be understood not in the actual but phenomenological sense [14]. Thirdly, the ecstatic nature of temporality opens up possibilities for the manifold expressions of human existence.

The contemporary culture is aimed at developing original ideas, new projects, innovative solutions, the implementation of which should make the lives of many people 
better. New concepts are the result of creative search and extraordinary solutions, the production of which is completely dependent on the person. Today, their development is focused on obtaining practical results that could not be achieved before. As noted by E. Balas "innovation is often defined by the common criteria of being novel, non- obvious, and useful" [7]. The changes taking place in modern culture should be understood not as a way of material enrichment and increasing comfort, but as a possibility to reveal his talents and prove himself for a person. Discovering the ecstatic and synthesizing nature of temporality, M. Heidegger directs man not only to the development of his inner world, but to the transformation of unproductive life position and creative self-realization.

\section{Conclusion}

Revealing perspectives the prospects for further development and improvement of culture, we must not only develop new technologies, but also take care of the person who creates them. We must not only create comfortable conditions for human life or provide a technical basis for scientific research. But we must understand that we will not succeed in developing innovations if people do not think freely and do not value creative work. According to E. Balas, "science and creativity need the diversity of people, cultures, and ideas" [7]. Therefore, it is necessary to reorient the person to change the current state of culture, to make discoveries and create new values. If person will guide by external circumstances and obey to the dictates of objective time, he will not be able to develop innovations. The new orientation of consciousness must be based on the research of the nature of temporality.

By the discovery of temporality the philosophers of the twentieth century initiated a new view of the image of human existence. They revealed those characteristics of the temporality which make human existence in time will always differ from the temporal existence of objects. Philosophers Revealing the essence of the dilemma of subjective and objective time, philosophers come to the conclusion that they are opposite as a synthesis and discreteness, dynamism and immobility, heterogeneity and homogeneity. However, the deep differences, existing between them, do not exclude their, interaction and mutual influence. Ch. Bouton believed that "human temporality is plastic, to the extent that it can be modified, assume different forms, exist according to different modalities" [2]. Temporality characterizes the changes of experiences in our inner world, but it is inseparable from our external existence. Our experiences of time and the time of our existence are one whole in which all moments are interconnected. If we come to the understanding that we are losing time, in this case our time has not yet begun and we need to comprehend the need for change in our lives. If we determine the time of our existence by the inner time of our consciousness, we cease to exist as consumers and become producers of new ideas. In the age of innovation and new technologies, relying on subjective time, we need to make a choice not to be superfluous people for their epoch.

\section{References}

1. G. Harman, Tool-being: Heidegger and the metaphysics of objects (Open Court, Chicago, 2002).

2. Ch. Bouton, Time and freedom (Northwestern University, Press, Evanston, 2014).

3. D. Beith, HORIZON: Phenomenological study, 7, 186 (2018).

4. V. Molchanov, Research on the phenomenology of consciousness (Publishing house "Territory of the future", Moscow, 2007).

5. N. Artemenko, Logos, 5, 55 (2010). 
6. A. Yampolskaya, HORIZON: Phenomenological study, 7, 576 (2018).

7. E. Balas, Innovative research of life science: pathways to scientific impact, public health improvement and economic progress (Wiley, Hoboken, 2019).

8. H. Bergson, Time and Free Will: an essay on the immediate data of consciousness (Dover publications, Mineola, 2001).

9. E. Husserl, Phenomenology and the crisis of philosophy (Harper \& Row Publishers, New York, 1965).

10. M. Heidegger, Being and time (State University of New York press, Albany, 1996).

11. Yu. Novikov, Metaphysics, 5, 21 (2013).

12. E. Husserl, On the phenomenology of the consciousness of internal time (1893-1917) (Kluwer academic publishers, Dordrecht. Boston. London, 1991).

13. M. Gusev, HORIZON: Phenomenological study, 8, 67 (2019).

14. D. Fedchuk, HORIZON: Phenomenological study, 3, 177 (2014). 